\title{
Dislocation Based Flow Stress Model of 300M Steel in Isothermal Compression Process
}

\author{
Rongchuang Chen ${ }^{(1)}$, Peng Guo, Zhizhen Zheng *, Jianjun Li and Fei Feng \\ State Key Laboratory of Material Processing and Die \& Mould Technology, Huazhong University of Science and \\ Technology, Wuhan 430074, China; crc@hust.edu.cn (R.C.); guop@hust.edu.cn (P.G.); \\ jianjun@mail.hust.edu.cn (J.L.); fengfei@hust.edu.cn (F.F.) \\ * Correspondence: zzz@hust.edu.cn; Tel.: +86-136-1866-0011; Fax: +86-027-8754-3490
}

Received: 14 May 2018; Accepted: 6 June 2018; Published: 8 June 2018

\begin{abstract}
The relationship between microstructure and flow behaviour has attracted attention from many researchers for the past decades, whilst the influences of dislocation and recrystallization on flow stress have not been well understood, which led to failure in flow stress prediction at high temperature compressions. In this work, we tried to provide a novel explanation of the relationship between microstructure evolutions and flow behaviour, and the influence of dislocation and recrystallization on flow stress was investigated. A dislocation based flow stress model was proposed and applied for $300 \mathrm{M}$ steel at the strain rate of $0.01-10 \mathrm{~s}^{-1}$ and the temperature of 950-1150 ${ }^{\circ} \mathrm{C}$. Results showed the established model could predict the flow stress both at constant strain rate conditions and at variable strain rate conditions. The present investigation is helpful to a better understanding of hardening and softening mechanisms in hot compression of $300 \mathrm{M}$ steel.
\end{abstract}

Keywords: dislocation; stress-strain relationship; grain size; isothermal compression

\section{Introduction}

The $300 \mathrm{M}$ steel is an ultra-high strength steel, which is developed from 4340 steel by adding silicon and vanadium. It is the most commonly used material in manufacturing of aircraft landing gear, pressure vessels, and fasteners in aerospace, nuclear, and other fields because of its excellent overall performance. In manufacturing of the $300 \mathrm{M}$ steel heavy forgings, the material undergoes sophisticated deformation procedures, and a deep understanding of flow behaviour was critical for the quality control both at the macroscopic level and at the microscopic level.

Many researchers have made plenty of efforts on a deeper understanding of the relationship between the deformation behaviour and the microstructure evolution. The Johnson-Cook model [1], Arrhenius model, and its improved models [2] have been used in the modelling of stress-strain relationships of materials, such as 20Cr2Ni4A [3], stainless steel [4], aluminum alloy [5], and GCr15 [6]. Fuzzy neural network has also been used in constitutive modelling of Ni-Ti alloy [7], aluminium alloy [8], and Titanium alloy [9]. However, the underlying mechanism of the influence of microstructure evolution on flow stress was not established. Zerilli et al. [10] proposed Zerilli-Armstrong (ZA) model for face center cubic (FCC) materials based on the thermal activated dislocation motion theory, and the ZA model has been successfully used in high strength steel [11], 20CrMo [12], and Ti6Al4V alloy [13]. Internal state variable model [14,15], Kocks-Mecking (KM) model [16] and other models $[17,18]$ were proposed to take into consideration of the influence of dislocation and recrystallization. But these models were not unified at different stages (the dynamic recovery stage and the dynamic recrystallization stage), and these models cannot be used in varying strain rates compressions. 
In the present investigation, a unified flow stress model will be provided to describe the hardening and softening mechanisms of $300 \mathrm{M}$ steel in recrystallization. Hot compressions will be carried out on a thermal compression machine, and the flow stress model parameters will be obtained. The model will be verified both at constant strain rate compressions and at variable strain rate compressions.

\section{Materials and Experimental Procedures}

\subsection{Materials}

The composition of the $300 \mathrm{M}$ steel is (weight percentage) $0.44 \% \mathrm{C}-0.80 \% \mathrm{Cr}-1.8 \% \mathrm{Ni}-0.78 \%$ Mn-1.64\% Si-0.35\% Mo-0.06\% V-balanced Fe. The initial state of the as-received material was annealed. The initial grains were equiaxed, and the initial phase was spheroidized pearlite, shown in Figure 1. The specimens were turned to cylindrical shape with the size of $8 \mathrm{~mm}$ in diameter and $12 \mathrm{~mm}$ in height.
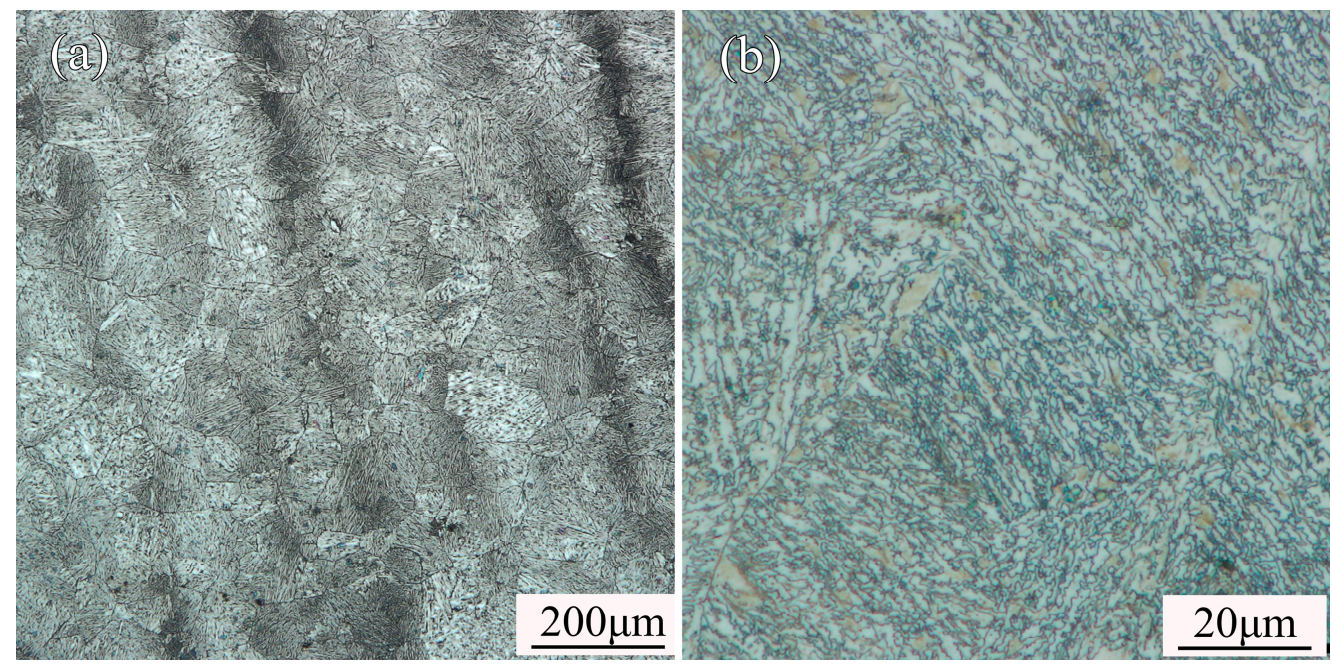

Figure 1. Microstructure of as-received 300M steel photographed on optical microscope showing:

(a) the initial grains were equiaxed and (b) the initial phase was spheroidized pearlite.

\subsection{Experiments}

Thermal compressions were carried out on a thermal compression machine (Gleeble 3500, Dynamic Systems Inc., Austin, TX, USA). The samples were heated to $1200{ }^{\circ} \mathrm{C}$ at $200{ }^{\circ} \mathrm{C} / \mathrm{s}$, held for $180 \mathrm{~s}$ to homogenize their microstructures, and then cooled to specific temperatures. The samples were compressed at 4 different strain rates $\left(0.01,0.1,1\right.$, and $\left.10 \mathrm{~s}^{-1}\right)$ and 5 different temperatures (950-1150 ${ }^{\circ} \mathrm{C}$ with $50{ }^{\circ} \mathrm{C}$ intervals) and quenched to maintain high temperature austenite grain boundaries. The true strain-stress curves were subject to noise reduction. The specimens were tempered at $560{ }^{\circ} \mathrm{C}$ for $2.5 \mathrm{~h}$. After air cooling, they were wire-electrode cut along the symmetrical plane passing through the cylinder axis. Grinding, polishing, and etching was adopted to obtain the microstructure. The etching solution contained $5 \mathrm{~mL}$ of saturated picric acid, $2 \mathrm{~mL}$ of detergent, $2 \mathrm{~mL}$ of carbon tetrachloride, and $0.15 \mathrm{~mL}$ of hydrochloric acid. After corrosion at $25{ }^{\circ} \mathrm{C}$, the center of the specimen was photographed using an optical microscope (VHX-1000C, Keyence Co., Osaka, Japan). The average grain size of as-received $300 \mathrm{M}$ steel was $37.7 \mu \mathrm{m}$.

\section{Results and Discussion}

\subsection{Deformation Behaviour}

Stress and strain relationships of 300M steel compressed at various temperatures and strain rates are shown in Figure 2. At the starting stage, the stresses increased in proportion to the strains due to 
dislocation pile-ups and cross-slips. When the stored energy of deformation increased to a critical value, dynamic recrystallization (DRX) occurred. The recrystallized grains nucleated at grain boundaries where the dislocation densities were high. Under the driving force of grain boundary curvature and deformation energy, grain boundaries of recrystallized grains migrated [19] and as a result, the overall dislocation density decreased, which led to the flow stress decreasing at the recrystallization stage. Then the work hardening effects and softening effect finally came to a balance [20] as the flow stress remained approximately unchanged.
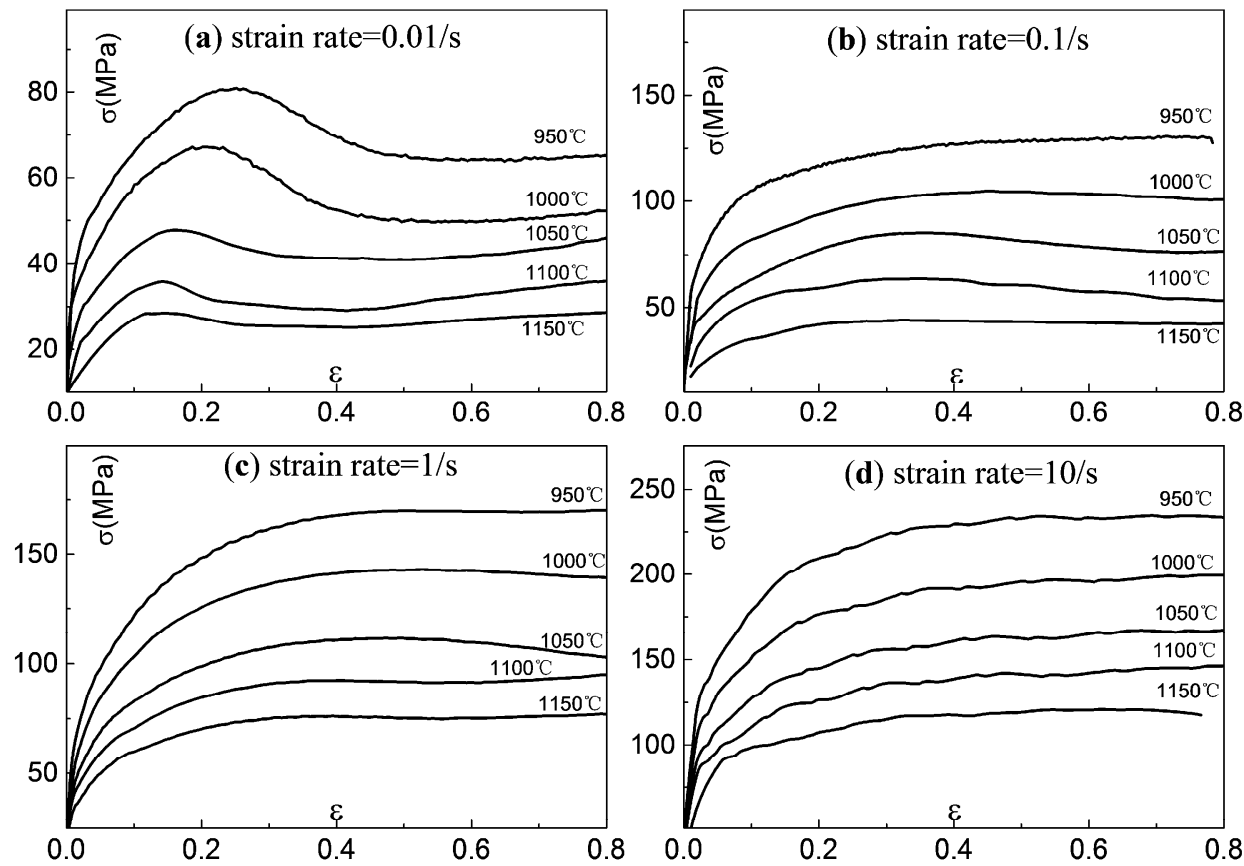

Figure 2. Stress-strain relationships of $300 \mathrm{M}$ steel compressed at different temperatures and strain rates: (a) $0.01 \mathrm{~s}^{-1},(\mathbf{b}) 0.1 \mathrm{~s}^{-1}$, (c) $1 \mathrm{~s}^{-1}$, and (d) $10 \mathrm{~s}^{-1}$.

As can be seen, the microstructure evolution played a very important role in flow behaviour of 300M steel, but yet very few models can be implemented which take into consideration of the influences of dislocation and recrystallization on flow stress. Therefore, a model accurately describing the flow behaviour of 300M steel is urgently needed.

\subsection{Microstructures Evolution}

The microstructure evolutions of $300 \mathrm{M}$ steel were investigated via etching, showing in Figures 3 and 4. At strain rate of $10 \mathrm{~s}^{-1}$ in Figure 3, the average grain sizes were 16.1, 27.8 and $42.2 \mu \mathrm{m}$, respectively. The grains were significantly refined at $1050{ }^{\circ} \mathrm{C}$ (Figure 3a) and almost all grains were recrystallized. It was interesting that recrystallizations did not refine the grains in Figure $3 c$, but led to grain coarsen at high temperatures, which was due to grain growth after recrystallization was completed, as could be seen from Figure $3 c$ that a few abnormal growth grains with size of $\sim 90 \mu \mathrm{m}$ emerged.

Figure 4 shows the microstructures of $300 \mathrm{M}$ steel deformed at $1150{ }^{\circ} \mathrm{C}$ to a strain of 1.2 . The average grain sizes were 78.0, 52.4, 46.2 and $42.2 \mu \mathrm{m}$, respectively. The grains were finer deformed at a higher strain rate, as seen in Figure $4 \mathrm{a}, \mathrm{d}$. This could be explained by that the recrystallization and grain growth took place simultaneously during compression, and if the strain rate was too small, the grain refinement effect by recrystallization could be reduced or overcome by the grain coarsen effect by grain growth. 

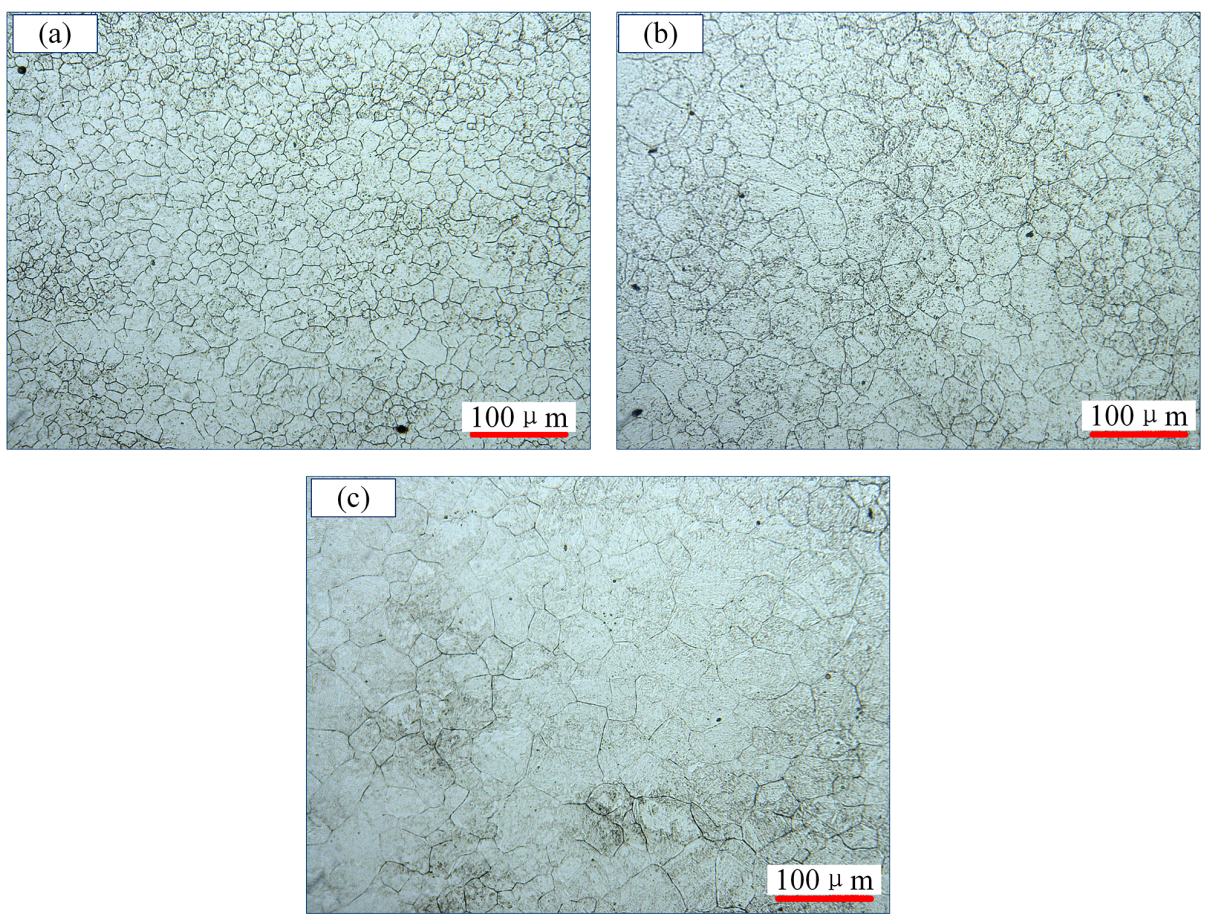

Figure 3. Microstructures of $300 \mathrm{M}$ steel deformed at $10 \mathrm{~s}^{-1}$ at: (a) $1050{ }^{\circ} \mathrm{C}$; (b) $1150{ }^{\circ} \mathrm{C}$; and (c) $1200{ }^{\circ} \mathrm{C}$.
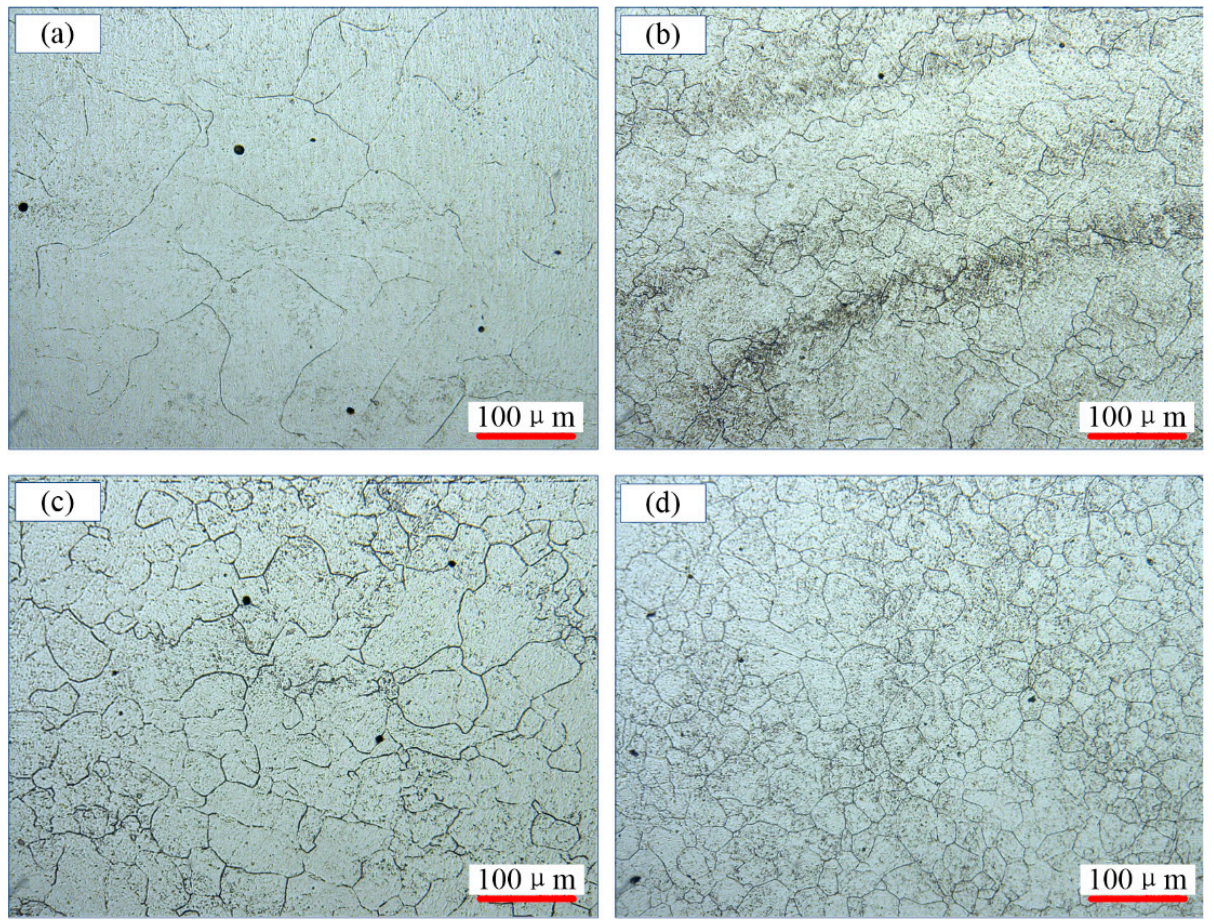

Figure 4. Microstructures of $300 \mathrm{M}$ steel deformed at the strain rate of: (a) $0.01 \mathrm{~s}^{-1}$; (b) $0.1 \mathrm{~s}^{-1}$; (c) $1 \mathrm{~s}^{-1}$; and (d) $10 \mathrm{~s}^{-1}$.

The microstructure evolution could be expressed by a volume fraction $(X)$ and the average grain size (d), which represented the progress of recrystallization and grain size variation in compression. The volume fraction $X$ could be expressed as [21]:

$$
X=1-\mathrm{e}^{-0.693\left(\frac{\varepsilon-\varepsilon_{c}}{\varepsilon_{p}}\right)^{n}}
$$


where $\varepsilon_{c}$ was the recrystallization critical strain, $\varepsilon_{p}$ was the peak strain of the stress-strain curve, and $n$ was a constant related to the rate of dynamic recrystallization. The values of $\varepsilon_{\mathcal{C}}$ and $\varepsilon_{p}$ could be obtained from the stress-strain curves and modelled as follows:

$$
\begin{aligned}
& \varepsilon_{c}=0.02738 \cdot\left(\dot{\varepsilon} \cdot e^{\frac{379800}{R T}}\right)^{0.04628} \\
& \varepsilon_{p}=0.0326 \cdot\left(\dot{\varepsilon} \cdot e^{\frac{379800}{R T}}\right)^{0.0602}
\end{aligned}
$$

The constant $n$ was determined to be 1.703 through regression of experimental values according to Equation (1).

The complete recrystallization grain sizes at different temperatures and strain rates could be obtained via metallography. The relationship between recrystallization grain sizes $\left(d_{d r x}\right)$ and deforming conditions represented by Zener-Hollomon parameter $(Z)$, in which the strain activation energy was calculated to be $379.8 \mathrm{~kJ} /(\mathrm{mol} \mathrm{K})$, is shown in Figure 5 .

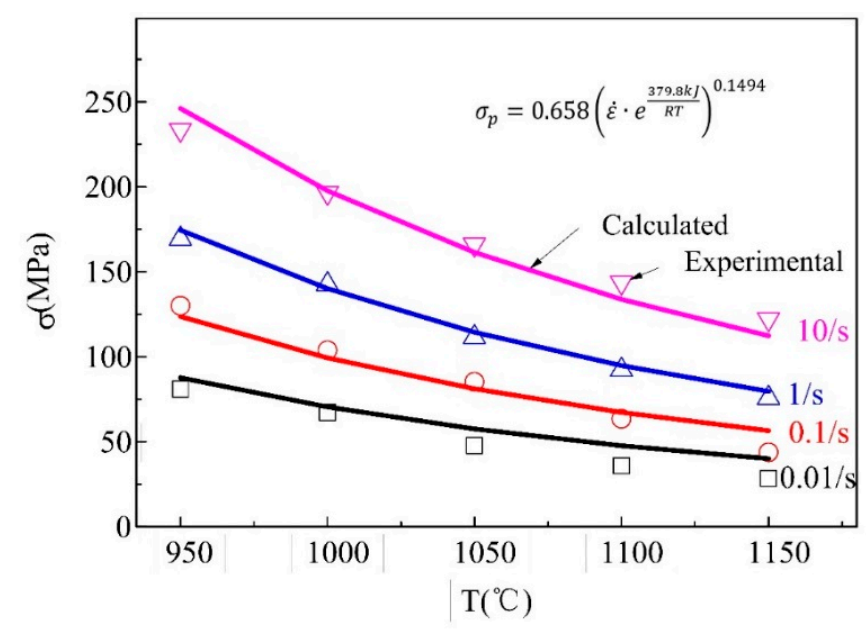

Figure 5. Fitting of peak stress to obtain the activation energy.

Therefore, the recrystallization grain sizes $\left(d_{d r x}\right)$ was:

$$
d_{d r x}=6568.2 \cdot\left(\dot{\varepsilon} \cdot e^{\frac{379800}{R T}}\right)^{-0.159}
$$

and the average grain size $(d)$ was expressed as:

$$
d=X d_{d r x}+(1-X) d_{0}
$$

where $d_{0}$ represented the initial grain size, which was $37.7 \mu \mathrm{m}$ determined by metallography.

\subsection{Dislocation Based Flow Stress Model}

The flow stress was closely related the dislocation motions, as described by the Taylor's equation [22-24].

$$
\sigma=\alpha \mu M b \sqrt{\rho}
$$

where $\sigma$ was the flow stress, $\alpha$ a constant, $\mu$ the shear modulus, $M$ the Taylor factor, $b$ the Burgess vector, and $\rho$ the average dislocation density. In the recovery stage, the dislocation density increment $(\Delta \rho)$ could be described by the contradicting effects of the strain hardening $\left(\Delta \rho_{s}^{+}\right)$which was caused by dislocation pile-ups and cross-slip, and the softening $\left(\Delta \rho_{s}^{+}\right)$by creep and dynamic recovery dislocation annihilations by the Kocks-Mecking (KM) model [16]: 


$$
\Delta \rho=\Delta \rho_{s}^{+}-\Delta \rho_{d r v}^{-}
$$

where $\Delta \rho_{s}^{+}$was dislocation increment by strain hardening, and $\Delta \rho_{d r v}^{-}$was dislocation decrement by dynamic recovery, which followed $[25,26]$ :

$$
\Delta \rho_{s}^{+}=\frac{M}{b}\left(\frac{\sqrt{\rho}}{k_{1}}+\frac{1}{d_{0}}\right) \Delta \varepsilon_{e f f}^{p} \text { and } \Delta \rho_{d r v}^{-}=k_{2} \rho \Delta \varepsilon_{e f f}^{p}
$$

where $d_{0}$ was the initial grain size, $k_{1}$ and $k_{2}$ coefficients, and $\Delta \varepsilon_{e f f}^{p}$ the effective plastic strain increment. It was argued by researchers $[27,28]$ that the dislocation-free recrystallized nuclei began to form and grow at grain boundaries under the driving force of grain boundary curvature and dislocations during dynamic recrystallization. But the dislocation model did not take into consideration of the dislocation decrement by dynamic recrystallization, which led to an inaccuracy in flow stress calculation. Therefore, the following model was proposed:

$$
\Delta \rho=\Delta \rho_{s}^{+}-\Delta \rho_{d r v}^{-}-\Delta \rho_{d r x}^{-}+\Delta \rho_{g}^{+}
$$

where the $\Delta \rho_{d r x}^{-}$represented the dislocation decrement by dynamic recrystallization, and $\Delta \rho_{g}^{+}$was introduced to take into consideration the Hall-Petch effect, which needed to be determined.

Dislocation annihilation due to recrystallization was nonnegligible for low stacking fault energy (SFE) materials, such as $300 \mathrm{M}$ steel $\left(11.4 \mathrm{~mJ} / \mathrm{m}^{2}\right)$, because for low SFE materials, the mobility of dislocations was lower, and the dynamic recrystallization was more likely to occur due to dislocation pile-ups in local areas [27]. As the recrystallized grains nucleated and grew at grain boundaries, the average dislocation densities of boundary swept regions decreased $[28,29]$, and the $\rho_{d r x}^{-}$was reasonably proportional to dynamic recrystallization volume fraction $(X)$ until the recrystallization completed. It could be assumed that the $\rho_{0}$ was the average dislocation densities of recrystallized grains as well as the as-received material, which was negligible compared with $\rho_{c}$, the critical dislocation density for recrystallization. The value of $\rho_{d r x}^{-}$followed:

$$
\rho_{d r x}^{-}=k_{3} X \rho_{c}
$$

The differentiated form obeyed:

$$
\Delta \rho_{d r x}^{-}=k_{3} \frac{\partial X}{\partial \varepsilon} \rho_{c} \Delta \varepsilon_{e f f}^{p} .
$$

In this way, the value of $\Delta \rho_{g}^{+}$remained to be determined in Equation (9). Dynamic recrystallization influenced the flow stresses not only by dislocation annihilation but also by grain sizes variation, as shown in researches $[30,31]$ that the relationship between flow stress and average grain size obeyed the Hall-Petch equation, to which the $\Delta \rho_{g}^{+}$followed a similar expression and the incremental form shows as follows:

$$
\rho_{g}^{+}=\frac{k_{4}}{b d}
$$

thus,

$$
\Delta \rho_{g}^{+}=\dot{\rho}_{g}^{+} \Delta \varepsilon_{e f f}^{p}=-\frac{k_{4}}{b d^{2}} \frac{\partial d}{\partial \varepsilon} \Delta \varepsilon_{e f f}^{p}
$$

where $k_{4}$ was a coefficient, and $b$ the Burgess vector. Although previous models [28-31] can separately calculate the flow stress in the dynamic recovery stage or dynamic recrystallization stage, no unified flow stress model covering the whole deformation stage has been reported. However, in the present model, at the dynamic recovery stage, both $\Delta \rho_{d r x}^{-}$and $\Delta \rho_{g}^{+}$equal 0 , and it was consistent with Kock-Mecking model. In recrystallization, the dislocation annihilation and grain size effect were incorporated. The form of the model was unified at different stages. 


\subsection{Model Parameter Determination}

The coefficients of the flow stress model $\left(k_{1}-k_{4}\right)$ could be expressed in the Arrhenius type:

$$
k_{i}=A_{i}\left(\dot{\varepsilon} \cdot e^{\frac{Q_{i}}{R T}}\right)^{n_{i}}
$$

where $i$ equaled 1-4 to represent $k_{1}-k_{4}$. The model parameters $\left(A_{i}, n_{i}, Q_{i}\right)$ could be determined in an iterative solution. The dislocation density for the $i+1$ th iteration was:

$$
\rho_{i+1}=\rho_{i}+\frac{M}{b}\left(\frac{\sqrt{\rho_{i}}}{k_{1}}+\frac{1}{d_{0}}\right) \Delta \varepsilon_{e f f}^{p}-k_{2} \rho_{i} \Delta \varepsilon_{e f f}^{p}-k_{3} \rho_{c} \frac{\partial X}{\partial \varepsilon} \Delta \varepsilon_{e f f}^{p}-\frac{k_{4}}{b d^{2}} \frac{\partial d}{\partial \varepsilon} \Delta \varepsilon_{e f f}^{p}
$$

where $\rho_{i}$ was the dislocation density of the $i$ th iteration, and $\Delta \rho_{i}$ the increase of dislocation, the value of which was obtained via experiment. The other parameters are shown in Table 1 . The critical dislocation densities for dynamic recrystallization was obtained via fitting:

$$
\rho_{c}=9.5479 \times 10^{8}\left(\dot{\varepsilon} \cdot e^{\frac{463520}{R T}}\right)^{0.2362} .
$$

The iterative solving, which was similar to multi-parameter nonlinear regression process, was implemented in MATLAB and the procedure is shown in Figure 6. Starting from a set of initial values, the flow stresses were calculated, and the model parameters were optimized to minimize the deviations using an algorithm which was a combination of derivative free method (DFM) and genetic algorithm (GA). The iterative solving results were shown in Table 2.

Table 1. Model parameters.

\begin{tabular}{cccc}
\hline Parameters & Value & Unit & Ref. \\
\hline$\alpha$ & 0.3 & - & {$[22]$} \\
$\mu$ & $86.94-0.027 \mathrm{~T}$ & $\mathrm{GPa}$ & {$[23]$} \\
$M$ & 3.06 & - & {$[22]$} \\
$b$ & $2.54 \times 10^{-10}$ & $\mathrm{~m}$ & {$[24]$} \\
\hline
\end{tabular}

Table 2. Iterative solving results.

\begin{tabular}{cccc}
\hline Parameters & $A_{i}$ & $n_{i}$ & $Q_{i}$ \\
\hline$k_{1}$ & $5.87 \times 10^{3}$ & $-1.83 \times 10^{-1}$ & $2.66 \times 10^{5}$ \\
$k_{2}$ & $1.35 \times 10^{1}$ & $-1.60 \times 10^{-3}$ & $-2.42 \times 10^{6}$ \\
$k_{3}$ & $1.19 \times 10^{-3}$ & $-2.88 \times 10^{0}$ & $2.17 \times 10^{4}$ \\
$k_{4}$ & $6.33 \times 10^{-43}$ & $-4.95 \times 10^{-1}$ & $-2.28 \times 10^{6}$ \\
\hline
\end{tabular}

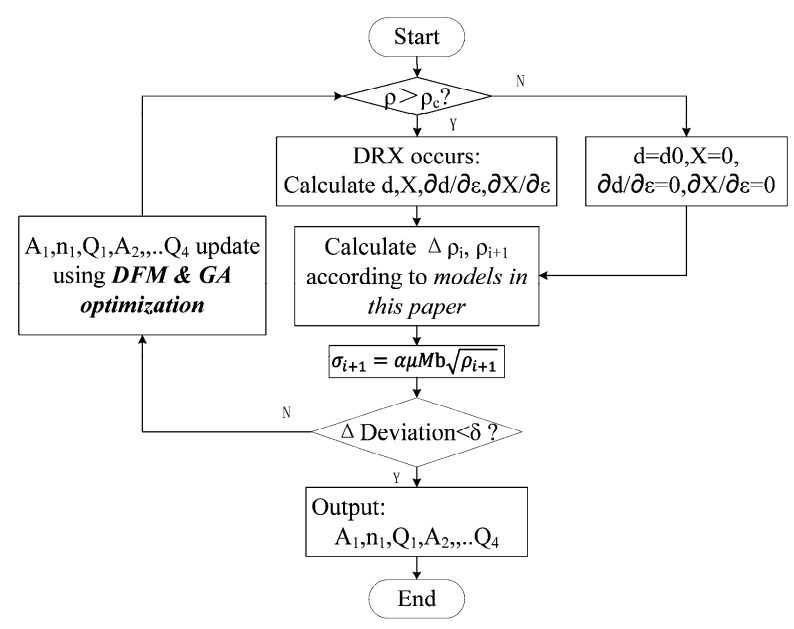

Figure 6. Iterative solving procedure. 


\subsection{Verification and Comparison}

Figure 7 shows the comparison of flow stress of $300 \mathrm{M}$ steel obtained by experiment and model calculation. The mean absolute and relative deviation were $5.37 \mathrm{MPa}$ and $6.59 \%$, respectively. A scatter plot drawn from experimental and calculated stresses (Figure 7f) showed that the model was accurate, and the $R$ value in representative of the confidence level was calculated to be 0.9824 . Minor deviations between the calculated and experimental flow stresses were found at low strain rates, which could be attributed to two reasons. Firstly, the optimization algorithm in this investigation tended to minimize the mean deviation of all flow stresses, resulting in a bigger percentage deviation at low strain rates. Secondly, some errors in experimental data may be caused by the drum effect of deformed specimens, the uneven temperature distribution, and the friction at both ends of the specimens. The Modified Arrhenius [2], Kock-Mecking [16], and Johnson-Cook [1] models were also employed, and the confidence levels were calculated to be $0.977,0.978$ and 0.972 , which showed that the model in this investigation has a slight advantage in precision. Besides, the model has successfully described the relationship between metal flow behaviour and microstructure evolution.
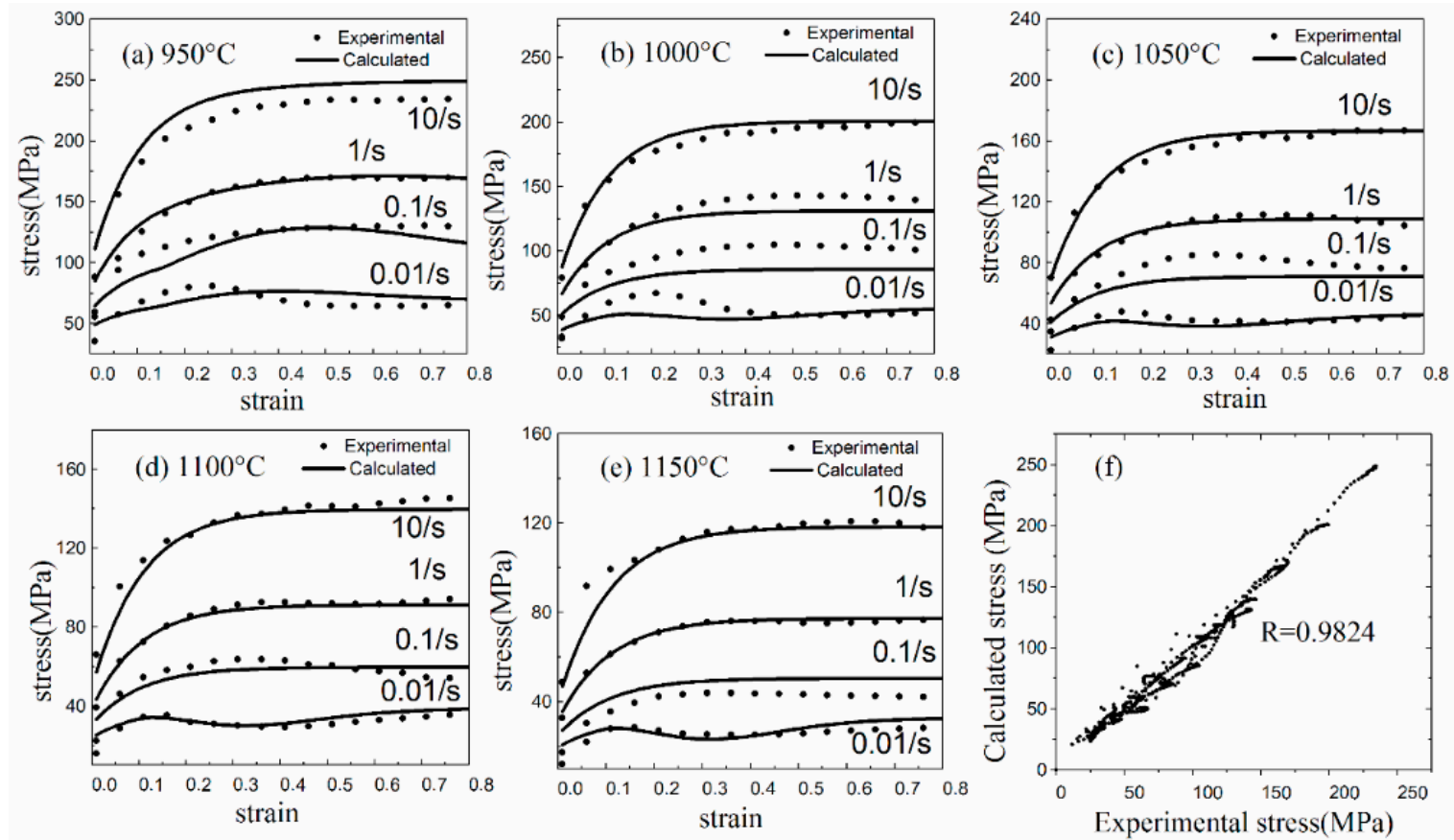

Figure 7. Comparison of experimental and calculated flow stress of $300 \mathrm{M}$ steel. (a) $950{ }^{\circ} \mathrm{C}$, (b) $1000{ }^{\circ} \mathrm{C}$, (c) $1050{ }^{\circ} \mathrm{C}$, (d) $1100{ }^{\circ} \mathrm{C}$, (e) $1150{ }^{\circ} \mathrm{C}$, and (f) a scatter plot drawn from experimental and calculated stresses.

In the final step, the model was adopted in flow stress prediction of a variable strain rate compression. The experimental strain rates varied from 1 to $0.1 \mathrm{~s}^{-1}$ whilst the temperature remained unchanged. The measured strain rate, the predicted flow stress, and the measured flow stress in the experiment were shown in Figure 8. The predicted flow stress agreed well with the experiment value. Therefore, the flow stress model proposed in this investigation was able to precisely calculate flow stress of $300 \mathrm{M}$ steel in variable strain rate compressions. 


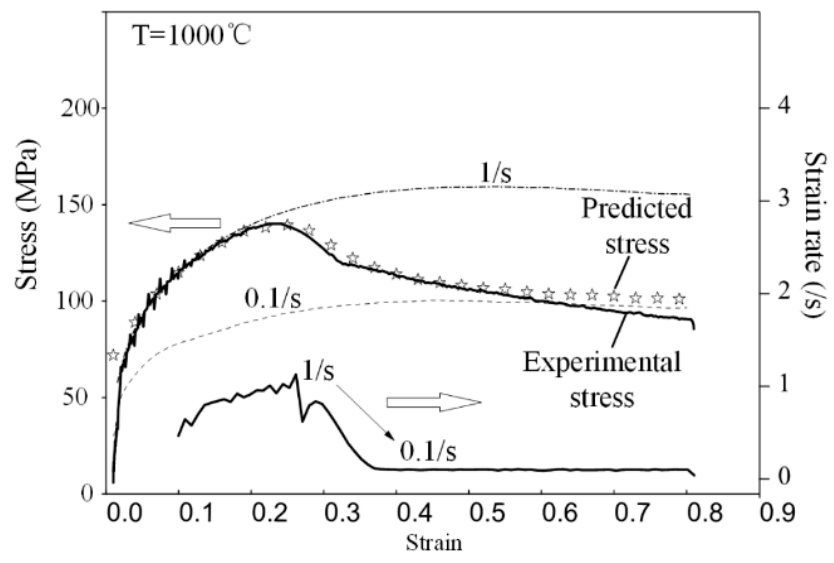

Figure 8. The measured strain rate, the predicted flow stress, and the measured flow stress of a variable strain rate compression.

\section{Conclusions}

The flow behaviour and microstructure evolution of $300 \mathrm{M}$ steel was investigated via isothermal compression at the strain rate of $0.01-10 \mathrm{~s}^{-1}$ and the temperature of $950-1150{ }^{\circ} \mathrm{C}$, and the following conclusions can be drawn:

(1) A dislocation based flow stress model was proposed to take into consideration of dynamic recrystallization and Hall-Petch effect. The model was unified both at the recovery stage and at the recrystallization stage.

(2) Microstructure evolution in dynamic recrystallization of $300 \mathrm{M}$ steel was established via metallography. The dynamic recrystallization of $300 \mathrm{M}$ steel was described in terms of the dynamic recrystallization volume fraction model and the average grain size model, which were determined by fitting.

(3) Flow stress model parameters were obtained by an iterative procedure implemented in Matlab software. A comparison between predicted and experimental flow stresses both at constant strain rate compressions and at variable strain rate compressions was made, and results showed a high precision in flow stress prediction of 300M steel.

Author Contributions: Conceptualization, R.C. and Z.Z.; Methodology, R.C. and Z.Z.; Software, R.C.; Validation, R.C. and Z.Z.; Formal Analysis, F.F.; Investigation, R.C., P.G.; Resources, J.L. and F.F.; Data Curation, P.G.; Writing-Original Draft Preparation, R.C.; Writing-Review \& Editing, P.G. and F.F.; Visualization, R.C.; Supervision, Z.Z. and J.L.; Project Administration, Z.Z.; Funding Acquisition, J.L. and F.F.

Funding: This work was funded by the National Natural Science Foundation of China (No. 51435007) and the China Postdoctoral Science Foundation (No. 2017M610472).

Acknowledgments: The authors appreciate the technique support from faculties of the Advanced Manufacturing and Technology Experiment Center in Huazhong University of Science and Technology.

Conflicts of Interest: The authors declare no conflict of interest.

\section{References}

1. Samantaray, D.; Mandal, S.; Bhaduri, A.K. A comparative study on Johnson-Cook, modified Zerilli-Armstrong and Arrhenius-type constitutive models to predict elevated temperature flow behaviour in modified 9Cr-1Mo steel. Comput. Mater. Sci. 2009, 47, 568-576. [CrossRef]

2. Li, H.; He, L.; Zhao, G.; Zhang, L. Constitutive relationships of hot stamping boron steel B1500HS based on the modified Arrhenius and Johnson-Cook model. Mater. Sci. Eng. A 2013, 580, 330-348. [CrossRef]

3. Wang, W.; Zhao, J.; Zhai, R.X.; Ma, R. Arrhenius-Type Constitutive Model and Dynamic Recrystallization Behavior of 20Cr2Ni4A Alloy Carburizing Steel. Steel Res. Int. 2016, 88, 1-9. [CrossRef] 
4. Mirzadeh, H. Constitutive modeling and prediction of hot deformation flow stress under dynamic recrystallization conditions. Mech. Mater. 2015, 85, 66-79. [CrossRef]

5. Quan, G.; Mao, Y.; Li, G.; Lv, W.; Wang, Y.; Zhou, J. A characterization for the dynamic recrystallization kinetics of as-extruded 7075 aluminum alloy based on true stress-strain curves. Comput. Mater. Sci. 2012, 55, 65-72. [CrossRef]

6. Yin, F.; Hua, L.; Mao, H.; Han, X. Constitutive modeling for flow behavior of GCr15 steel under hot compression experiments. Mater. Des. 2013, 43, 393-401. [CrossRef]

7. Shu, X.; Lu, S.; Wang, K.; Li, G. A comparative study on constitutive equations and artificial neural network model to predict high-temperature deformation behavior in Nitinol 60 shape memory alloy. J. Mater. Res. 2015, 30, 1988-1998. [CrossRef]

8. Yang, Y.Y.; Linkens, D.A.; Mahfouf, M. Genetic algorithms and hybrid neural network modelling for aluminium stress-strain prediction. Proc. Inst. Mech. Eng. 2003, 217, 7-21. [CrossRef]

9. Srinivasu, G.S.; Rao, R.N. Artificial neural network approach for prediction of stress-strain curve of near $\beta$ titanium alloy. Rare Met. 2013, 33, 249-257. [CrossRef]

10. Zerilli, F.J.; Armstrong, R.W. Dislocation-mechanics-based constitutive relations for material dynamics calculations. J. Appl. Phys. 1987, 61, 1816-1825. [CrossRef]

11. Lin, Y.C.; Chen, X.-M. A combined Johnson-Cook and Zerilli-Armstrong model for hot compressed typical high-strength alloy steel. Comput. Mater. Sci. 2010, 49, 628-633. [CrossRef]

12. He, A.; Xie, G.; Zhang, H.; Wang, X. A modified Zerilli-Armstrong constitutive model to predict hot deformation behavior of 20CrMo alloy steel. Mater. Des. 2014, 56, 122-127. [CrossRef]

13. Cai, J.; Wang, K.; Han, Y. A Comparative Study on Johnson Cook, Modified Zerilli-Armstrong and Arrhenius-Type Constitutive Models to Predict High-Temperature Flow Behavior of Ti-6Al-4V Alloy in $\alpha+$ $\beta$ Phase. High Temp. Mater. Process. 2016, 35, 297-307. [CrossRef]

14. Puchi-Cabrera, E.S.; Guérin, J.-D.; Dubar, M.; Staia, M.H.; Lesage, J.; Chicot, D. Constitutive description for the design of hot-working operations of a 20MnCr5 steel grade. Mater. Des. 2014, 62, 255-264. [CrossRef]

15. Chen, X.-M.; Lin, Y.C.; Wen, D.-X.; Zhang, J.-L.; He, M. Dynamic recrystallization behavior of a typical nickel-based superalloy during hot deformation. Mater. Des. 2014, 57, 568-577. [CrossRef]

16. Mecking, H.; Kocks, U.F. Kinetics of flow and strain-hardening. Acta Metall. 1981, 29, 1865-1875. [CrossRef]

17. Pesin, A.; Korchunov, A.; Pustovoytov, D. Numerical Study of Grain Evolution and Dislocation Density during Asymmetric Rolling of Aluminum Alloy 7075. Key Eng. Mater. 2016, 685, 162-166. [CrossRef]

18. Florando, J.N.; El-Dasher, B.S.; Chen, C.; Swift, D.C.; Barton, N.R.; McNaney, J.M.; Ramesh, K.T.; Hemker, K.J.; Kumar, M. Effect of strain rate and dislocation density on the twinning behavior in Tantalum. AIP Adv. 2016, 6, 1-157. [CrossRef]

19. Goetz, R.; Seetharaman, V. Modeling Dynamic Recrystallization Using Cellular Automata. Scr. Mater. 1998, 38, 405-413. [CrossRef]

20. Kim, S.-I.; Yoo, Y.-C. Dynamic recrystallization behavior of AISI 304 stainless steel. Mater. Sci. Eng. A 2001, 311, 108-113. [CrossRef]

21. Laasraoui, A.; Jonas, J.J. Prediction of steel flow stresses at high temperatures and strain rates. Metall. Trans. A 1991, 22, 1545-1558. [CrossRef]

22. Gurla, P.V.S.S. An Improved Dislocation Density Based Work Hardening Model for Al-Alloys; Aachen University: Aachen, Germany, 2007.

23. Liu, J.; Edberg, J.; Tan, M.J.; Lindgren, L.E.; Castagne, S.; Jarfors, A.E.W. Finite element modelling of superplastic-like forming using a dislocation density-based model for AA5083. Model. Simul. Mater. Sci. Eng. 2013, 21, 25006-25028. [CrossRef]

24. Svoboda, A.; Wedberg, D.; Lindgren, L.-E. Simulation of metal cutting using a physically based plasticity model. Model. Simul. Mater. Sci. Eng. 2010, 18, 1825-1830. [CrossRef]

25. Evers, L.; Brekelmans, W.A.; Geers, M.G. Scale dependent crystal plasticity framework with dislocation density and grain boundary effects. Int. J. Solids Struct. 2004, 41, 5209-5230. [CrossRef]

26. Lin, Y.C.; Wen, D.-X.; Chen, M.-S.; Liu, Y.-X.; Chen, X.-M.; Ma, X. Improved dislocation density-based models for describing hot deformation behaviors of a Ni-based superalloy. J. Mater. Res. 2016, 31, 2415-2429. [CrossRef]

27. Humphreys, F.J.; Hatherly, M. Chapter 2. The Deformed State. In Recrystallization and Related Annealing Phenomena; Elsevier: Amsterdam, The Netherlands, 2004; Volume 64, pp. 219-224. 
28. Chen, F.; Cui, Z.; Chen, S. Recrystallization of 30Cr2Ni4MoV ultra-super-critical rotor steel during hot deformation. Part III: Metadynamic recrystallization. Mater. Sci. Eng. A 2011, 528, 5073-5080. [CrossRef]

29. Liu, Y.-X.; Lin, Y.C.; Li, H.-B.; Wen, D.-X.; Chen, X.-M.; Chen, M.-S. Study of dynamic recrystallization in a Ni-based superalloy by experiments and cellular automaton model. Mater. Sci. Eng. A 2015, 626, 432-440. [CrossRef]

30. Puchi-Cabreraabc, E.S.; Guérind, J.D.; Dubard, M.; Staiaab, M.H.; Lesagec, J.; Chicotc, D. Constitutive description of Fe-Mn23-C0.6 steel deformed under hot-working conditions. Int. J. Mech. Sci. 2015, 99, 143-153. [CrossRef]

31. Lao, L.; Ruimi, A.; Zbib, H.M. A dislocation-based model for deformation and size effect in multi-phase steels. Int. J. Plast. 2015, 72, 44-59. [CrossRef]

(C) 2018 by the authors. Licensee MDPI, Basel, Switzerland. This article is an open access article distributed under the terms and conditions of the Creative Commons Attribution (CC BY) license (http:/ / creativecommons.org/licenses/by/4.0/). 